\title{
Euthanasia, withholding life-prolonging treatment, and moral differences between killing and letting die
}

\author{
Raanan Gillon Imperial College and King's College, London University
}

Several papers in this issue relate to the questions of or as some would have it, the question of -(a) when and why to forego life-prolonging treatment and (b) whether intentional killing of patients who want to die can ever be justified, let alone legalised. Arguments about these questions have also been rehearsed recently in the British Medical Association's (BMA) report on euthanasia (1), in the Hastings Center's Report on foregoing treatment (2), and at a valuable international conference held at Lawrence University in Appleton, Wisconsin, in which doctors and ethicists from ten countries, mostly in Europe and America, sought areas of agreement on these matters (3).

As Gavin Fairbairn points out in this issue of the journal (4), what is morally true of acts causing death is equally true of omissions causing death, 'other things being equal'. The qualification is vital, for 'other things' often are not equal, yet discussion in contemporary medical ethics seems increasingly to ignore this fact and move to the unqualified claim that killings are necessarily morally equivalent to lettings die. Were that true then medical decisions to forego lifeprolonging treatment resulting in an earlier death than would have occurred had treatment been given would necessarily be morally equivalent to decisions to kill resulting in the same reduction of life-span.

In analysing these issues it is thus important to distinguish between two quite different claims. The first is that there is a necessary moral equivalence between killing and letting die. The second is that there is a necessary moral difference between killing and letting die. Both claims are false but it is only the second to which contemporary philosophers have addressed themselves, demonstrating unequivocally that there is no necessary moral difference between killing and letting die. The famous example offered by James Rachels (5) in which one villain drowns his young cousin in order to inherit while another, intending to do the same is spared the effort because his cousin falls in his bath, hits his head and drowns 'naturally', is one of many that show there can be no necessary moral difference between killing and letting die. This is an important conclusion to hammer home to those who simplistically assume that just because a death results from an omission to do something it is morally preferable to a death that results from doing something; who assume, for example, that a death thatके results from not connecting a patient to a respirator is $\overrightarrow{+}$ necessarily morally preferable to a death that resultsicu from disconnecting a patient from a respirator.

However, from the conclusion that there is no necessary moral difference between killing and letting ? die it simply does not follow that they are necessarily $\vec{C}$ morally equivalent; all that follows is that there are cases where letting die is morally equivalent to killing ${ }_{\mathbb{D}}$ (and of course vice versa). Plenty of counterexamples 3 are available to demonstrate that it would be equally吕 absurd to claim that killing is necessarily morally $\vec{\circ}$ equivalent to letting die - as Philippa Foot pointed oft so long ago, sending poisoned food to starving peopte in the underdeveloped world is clearly worse thāं allowing them to die of starvation by not sending thems food (6). If a doctor kills his patient in order to get awayō for the weekend or because he wants to free a bed foro the next 'take' that is clearly wrong; yet not ${ }^{\circ}$ resuscitating the same patient because he or she is in $\overrightarrow{\vec{O}}$ persistent vegetative state or because he or she has 3 refused resuscitation may well be morally required. It is probably safe to assert that there are no arguments in the philosophical literature that explicitly set out to show that killing is necessarily morally equivalent tod letting die, tout court, let alone that succeed in doing so. $\frac{5}{3}$ (Papers purporting to falsify this claim will be welcomed - though not without astonishment!). But of course it is true that where there are no morally? relevant differences (ie 'other things being equal') thens killing and letting die are morally equivalent: that is an analytic truth, true by virtue of the language used, but it is not an enlightening truth and on the contrary tendsNo to be a very misleading one.

Medicine, law and everyday morality distinguish clearly between a strong universal though prima faciew prohibition on killing and a very much more equivocalo attitude to letting die. The assumption underlying thiso general approach seems to be that all of us owe a strong prima facie duty to all others not to kill each other but: that we may or may not, depending on the circumstances and the relationships involved, owe aे duty to each other to preserve each other's lives. $\stackrel{?}{?}$ Expressed in rights language the assumption may be $\mathbb{\complement}$ put thus: all of us have a strong prima facie right against all others that they must not kill us: we may or may not 
have rights against others that they prolong our lives, depending on who those others are, our relationships with them, and the particular circumstances.

Are there any moral justifications that underpin this common tendency to distinguish morally between killing and letting die or is it mere unsupported intuition and custom? Since the desire to undermine the distinction is most often manifested by consequentialist philosophers it may be best to start with consequentialist justifications for maintaining it.

The first is that so long as most killings continue to be perceived by most people as being far worse than most lettings die (at present an indisputable empirical fact), it is from a consequentialist point of view important - case for case - to concentrate on prevention of killings more than on prevention of allowings to die, whether or not people are right in their perception of such an important difference between the two. For given such perceptions, the prevention of a killing will produce more benefit than the prevention of a letting die.

Secondly, it is probably true to say that more resources are usually necessary for the prevention of a letting die than for the prevention of a killing (ie keeping people alive when they would otherwise die is likely to require more resources, especially in the medical context, than stopping people killing others typically requires). So once again from a consequentialist point of view it would seem likely to maximise welfare and thus be better if we continued to differentiate morally between killing and letting die and concentrated on preventing the former by maintaining a powerful prima facie moral prohibition on killing.

The third consequentialist justification for distinguishing morally between killings and lettings die is that in the large majority of cases killing people harms them in comparison with letting them go on living. Conversely while this is also often true about not trying to keep people alive, there are very many cases (especially and increasingly so in the medical context) in which letting people die harms them less than keeping them alive - and trying to keep them alive would harm them. So while a general injunction against killing people can easily be seen to conduce to maximising welfare (it is a further question to be considered below whether the injunction should extend to voluntary euthanasia) it seems highly unlikely that an equivalent general injunction to keep people alive wherever possible would also maximise welfare.

A fourth, and in medicine particularly important, moral difference between the moral injunctions against killing and against letting die rests on the moral assumption that people's autonomy ought to be respected, in so far as such respect is compatible with respect for the autonomy of all affected. This principle is supportable from both consequentialist and deontological moral perspectives. Now it might be thought that respect for autonomy is neutral between killing and letting die, but this is surely not the case, for while a doctor who imposes life-prolonging treatment on a patient who competently rejects it is clearly failing to respect the patient's autonomy, a doctor who refuses a patient's request to be killed does not infringe the patient's autonomy (except in very rare cases where the patient is unable to kill himself). Autonomy is after all by definition self-rule and the patient's ability (and indeed in Britain legal right) to kill himself is not, except in the rare cases indicated, infringed by the doctor's refusal. On the contrary, in cases where the doctor has a moral objection to killing it would infringe the doctor's autonomy if he were required to kill the patient, albeit at the patient's competent request.

Equally the doctor would infringe the patient's autonomy by imposing treatment, including lifeprolonging treatment, against the patient's will. This last argument can be expressed even more strongly in rights language in a way that should be persuasive to anyone who believes that people have a right not to be confined in hospitals, given medicines, operated on or subjected to any other form of medical treatment, against their will (assuming that danger to others is not involved and assuming that they are sufficiently in their right mind not to be properly regarded as mentally incompetent to make autonomous decisions).

Seen from the perspective of medical ethics - with its central concern to benefit patients medically with minimal harm (or without undue burden) in the context of respect for the patients' autonomy and the need to act justly - there seems little doubt that doctors must not do things to patients against the patients' will. Doctors offer their services, they don't and should not impose them, even to prolong life (given the standard provisos alluded to above). Thus the withholding of life-prolonging medical treatment when the competent patient refuses it is not only morally permissible but morally required, a conclusion shared by the BMA, the Hastings Center Report and the Appleton international consensus.

Voluntary euthanasia - the deliberate ending of life in the context of severe and incurable disease at the competent request of the patient - continues to be rejected by most 'official' medical ethics pronouncements, including that of the BMA, with the exception of official Dutch medical ethics and de facto Dutch law, for both of which it is acceptable provided it is carried out according to guidelines agreed between the Dutch medical and legal authorities. Here the deliberations of the Appleton international conference are instructive, for the consensus accepted that requests for voluntary euthanasia might, where incurable disease and suffering were involved, be morally justified. However all the participants, including the Dutch (two of whom movingly described the intolerable circumstances of patients for whom they had administered euthanasia under the terms of the Dutch guidelines) agreed that it was safer for statutes against intentional homicide to remain in force. 
The Dutch believed nonetheless that there should be a mechanism such as their own whereby doctors in strictly specified circumstances should not be prosecuted - somewhat as, to give a less weighty analogy, offered by Jean Davies in this issue of the journal (7), members of the emergency services are not prosecuted for jumping red lights in the course of attending emergency calls, though the law against doing so remains. This, however, was to go too far for most of the other participants at Appleton, for whom the importance of the general prohibition of killing people outweighed the benefits of permitting doctors to do so, even in those cases where requests for such voluntary euthanasia were morally justifiable - and where to accede to them better fitted the description 'helping to die' rather than 'killing', to use the distinction proposed by Jean Davies (7).

Much of the opposition to voluntary euthanasia turns on slippery-slope worries. The Dutch have instituted a social experiment which in the coming years should give some indication of how justified or how exaggerated such worries are. Meanwhile spurious philosophical claims or suggestions that when doctors forego life-prolonging treatment their omissions are necessarily morally equivalent to killing their patients must be rejected: in particular such ideas should not be allowed to bolster nonsensical notions that somehow doctors fall into the same moral camp as murderers unless they do all they possibly can to prolong their patients' lives, regardless of their patients' wishes, regardless of the burdens on thet patients, regardless of the costs and opportunity costs $\overrightarrow{5}$. to others, regardless of the quality of life prolonged ande? regardless of the probabilities of achieving such prolongation. Such a result would indeed be $a^{\text {p }}$ disastrous misinterpretation of the now uncontentious? claim that there is no necessary moral difference between killing and letting die.

\section{References and notes}

(1) Euthanasia - Report of a British Medical Asscciation working party. London: British Medical Association, $\overrightarrow{0}$ 1988.

(2) Guidelines on the termination of life-sustaining treatment and $\vec{\omega}$ the care of the dying - a report by the Hastings Center? Briarcliff Manor, NY. The Hastings Center, 1987.

(3) An international consensus statement on foregoing lifeprolonging treatment (in press). Correspondence in advance of publication to Professor J Stanley, Edward F Mielke, Professor of Ethics in Medicine Science and $\vec{\overrightarrow{ }}$ Society, Lawrence Univeristy, Appleton, Wisconsin 54912, USA.

(4) Fairbairn G J. Kuhse, Singer and slippery slopes. $-\vec{C}$ Fournal of medical ethics 1988; 14: 132-134.

(5) Rachels J. Active and passive euthanasia. New Englando journal of medicine 1975; 292: 78-80 (and variously reprinted).

(6) Foot P. The problem of abortion and the doctrine of the double effect. Oxford review 1967; 5: 5-15 (and variously $\vec{c}$ reprinted).

(7) Davies J. Raping and making love are different concepte so are killing and voluntary euthanasia. Fournal of mediex ethics 1988; 14: 148-149. 